\title{
When I Dance My Walk: A Phenomenological Analysis of Habitual Movement in Dance Practices
}

\author{
Carolina Bergonzoni, \\ Arts Education, Simon Fraser University, Vancouver, Canada \\ Email: cbergonz@sfu.ca
}

\section{Abstract}

In this article, I describe the experience of dancing-a-walk. My specific focus is on the shift that I perceive in my body when I dance-a-walk rather than functionally walking. Following a firstperson perspective, I demonstrate how my experience of practicing dancing-a-walk interrogates the habit of walking and makes it come alive again as an expression of the body. First, I show how the practice of dancing-a-walk challenges the dichotomy between abstract and concrete movement proposed by Maurice Merleau-Ponty in the Phenomenology of Perception. Indeed, dancing-a-walk is an example of a concrete and yet already abstract movement. Then, I turn to concepts such as habits and body memory. By identifying how the perception of my body changes when I dance everyday movements (i.e., walking) versus when I execute such movements functionally, I aim to develop a new perspective on and vocabulary for a phenomenological definition of concrete/abstract movements within the context of dance.

\section{Introduction}

As a trained dancer, I often, indeed almost always, ask myself: What is that which constitutes dance? What is that which transforms movement into dance? For the past year, I have been exploring three of the most basic, quotidian movements used in dance improvisation, namely, walking, standing, and lying down, with the aim of discovering new insights on these questions. For this article, I will only take into account my investigation of walking. Specifically, my interest is in the different ways I perceive my body when walking and when dancing-a-walk. This interest took hold one day when I was walking along the seawall in Vancouver on my way to a dance class. Taking one step after the other, I became curious as to how I could take advantage of that walk. How could I use that time to warm-up my dancing being? I decided to start dancing on the street, although it was a way of walking that did not look like a 'dance.' Through a phenomenological analysis of this dance, and specifically of dancing-a-walk, I argue 
that concrete movements, as defined by Maurice Merleau-Ponty, are already abstract. To dancea-walk is to perform a habitual movement in an always abstract behaviour. It is to be open to the possible, as opposed to the actual.

I am writing from the perspective of a non-injured, dance trained, and able-bodied person. From this standpoint, learning how to walk was one of the developmental steps that occurred when I was a child. I do not have any memory of the process. What I know is that after walking became a habit, I did not have to think about how to walk anymore. In this article, I use the practice of dancing-a-walk to bring this habit to life again. Following the phenomenological approach of "making the familiar strange" (Sheets-Johnstone, 1999), I illustrate how a phenomenological description of dancing-a-walk, and the consequent analysis of what it is that transforms a movement into a 'dance' movement, complicates the division of abstract and concrete movements proposed by Merleau-Ponty. Sheets-Johnstone (1999) affirms:

Calling attention to ourselves in movement in this way [by performing free variations on our own habitual movement patterns to appreciate first-hand what is kinetically there], we have the possibility of discovering what is invariantly there in any felt experience of movement. This is because whatever the habitual movement, it now feels strange, even uncomfortable. Just such oddness jars us into an awareness of what we qualitatively marginalize in our habitual ways of doing things. By making the familiar strange, we familiarize ourselves anew with the familiar (p. 143).

I let my body become the research site during this process. I allowed kinaesthetic sensibilities to provide me with new research questions, such as: What is it that changes the attitude, or the style, of my own body? What does my body perceive when walking or dancingmy-walk? During my explorations over the last year, I often had the urge to stop and write. I took notes of the different attitudes that I experienced. These notes became an essential part of my exploration and research of the topic. Every bodily movement, including walking, is expressive. However, once the movement becomes a familiar habit, we tend to forget that there still remains the creative act. Walking involves, moreover, what Merleau-Ponty $(1942 ; 1945)$ defines as "style" or a way of being-in-the-world; it is an aspect of our existence that it is embodied. Indeed, our walk - and even more so the way we dance-a-walk - is a hint for understanding how certain behaviour and a certain style arise in us. Linda Singer (1981) uses Merleau-Ponty's example of a painter's style to describe how "style is a lived and engaged phenomenon" that might not be readily apparent. "When he is working, the artist's style remains largely implicit - inseparable from his way of seeing the world and gesturing with his brush" (p. 155). Even though there is an explicitly creative expression when I dance-a-walk, I am generally unaware of my style in the same way that I am not aware of it when I am walking functionally.

It is important to clarify that what I experienced and what is now the focus of my research has nothing to do with the "dance-walking" phenomenon started by Ben Aaron around 2012. Aaron proposed a fitness exercise that could be done in the street or in public spaces. His idea was to bring together dance and whole body movements while "walking." I argue that what the dance-walkers do is travel through space while moving their whole body in dance-like movements. But travelling from point A to point B is different than walking. I can move from point $A$ to point $B$ with a wide variety of actions: walking, jumping, running, hopping, or crawling. On the contrary, the dance-walk that I take into account in this article does not look like a fitness exercise. Perhaps it does not even look like a dance at all. It looks like a walk. The 
movement is nothing more than what I normally do when I walk, with one foot stepping in front of the other.

My interest is in the shift of intentionality that occurs when I dance-my-walk. While walking, I wonder if people around me can see my dance and perceive the shift of energy that happens in my body. Can they perceive the change in my physical attitude, posture, and behaviour? This change of intention, attention, muscular tension, and ability to feel the whole body is extremely clear for me, but is it visible from outside? When dancing-my-walk, I perceive a familiar shift of energy and intentions in my body that I recognize as a dance. For the purpose of this article, I define walking as an unreflective, habitual movement that does not need focus or explicit attention; it flows by itself without being guided by reflective thoughts. On the other hand, to dance-a-walk is explicitly expressive even though the action (walking) itself is still is unreflectively habitual. To dance-a-walk requires commitment, concentration, focus, and the explicit intention of transforming the action of walking into an expressive walk.

\section{Bodily Movement - Concrete to Abstract Attitudes}

In The Structure of Behavior (1942), and more extensively in Phenomenology of Perception (1945), Merleau-Ponty proposed a distinction between abstract and concrete movement based on the case of Schneider, a brain damaged soldier. According to the philosopher, abstract movements are only possible when a concrete movement has become habitual. It occurs only when a habit becomes part of the sensorimotor schema of the body. In this process, the body schema transforms and enriches its movement possibilities. The familiarity with the action allows human beings to be open to an imaginary world full of multiple possibilities. Abstract movements occur within "the possible or within non-being" (Merleau-Ponty, 1945/2012, p. 114); these movements evoke abstract situations and create their own background. Abstract movements are not functional nor directed since when one carries off these movements, the body is exposed to a world of possibilities, which requires an ability of projection. By contrast, concrete movements are related to direct actions and those that serve immediate necessities. Concrete movements are habitual and occur "within being or within the actual" (p. 114), and they "adhere to a given background" (p. 114). Concrete movements are related to an attitude of the body, also defined as "style" by Merleau-Ponty (1945). However, the key difference between concrete and abstract movement is in the space in which the movement takes place. For the former, it is the background of the action. Concrete movements occur in "the given world" whereas "the background of abstract movement is, on the contrary, constructed" (p. 113).

Although my experience is not comparable with the clinical case of Schneider discussed by Merleau-Ponty (1945), I demonstrate how a phenomenology of dance, specifically of dancing-a-walk, threatens the dichotomy expressed by the philosopher and aims to generate new insight. To overcome this dichotomy, Timothy Mooney (2011) offers an alternate terminology to clarify the explanation of Schneider's preponderance of concrete movements. Mooney (2011) proposes three categories of movement: habitual, abstract, and concrete-like. The first category of movement, defined by Mooney as "concrete and context-familiar" (p. 360), refers to the habitual actions that Schneider was able to perform, such as scratching a mosquito bite. Abstract movements include those Schneider was asked to perform in response to verbal requests, but is unable to execute, such as pointing to his nose. What is new, in Mooney's definitions, is the idea of "concrete-like and context-strange" movements (p. 363). With this terminology, the author 
indicates the movements that are habitual, but also ones that a patient affected by illness can only perform in their actual situations. For example, Schneider was not able to comb his hair on command, but he could perform the action as part of his morning routine. He was not able to mimic a military salute without detaching himself from the actual situation. Mooney (2011) writes:

If asked to mimic a salute, he [Schneider] has to stand up and adopt a military posture, as if on a parade ground. He cannot abbreviate these actions, showing no economy in his movements. In his consciousness, he has to project himself into situations in which such movements would be concrete and context-familiar, and throw his entire body into the mimes. (p. 362)

Following Mooney's terminology, I propose that to dance-a-walk is a concrete and context-familiar movement that also changes the relation to space. The dance-a-walk occurs in the performer's own constructed world, therefore, the movement becomes a form of delight that transforms the use of imagination and the use of the body. When performing abstract movements, the body becomes a powerful form of expression since its aim is the movement itself. When we are not forced to move our body with a purpose, it seems we can play with it and transform the actual world by immersing ourselves in imaginary situations.

Komarine Romdenh-Romluc (2007) used the example of a rock-face, which is perceived as climbable by a climber, to support Merleau-Ponty's (1945) idea that 'the subject's surrounding and current task bring relevant motor skills 'online' making them available for the subject to use in perception and action" (p. 52). When the rock-climber perceives the rock-face as climbable, they have the power to access the skills to actually climb it. When I am dancingmy-walk, however, I am not enacting a walk or a specific skill. I am walking as I would normally, but I shift my intention and therefore my self-awareness so that the walk becomes an explicitly expressive dance. Walking is a concrete movement in terms of its familiarity to me. When I walk, I do not have to think about the action anymore. My legs are simply moving, one after the other. I trust my body knows what to do, and I let it walk in the most functional way possible. Generally speaking, I follow a direction and an intention. I am moving towards a point in space, going from point A to point B. Without any doubt, I am in a concrete attitude since I am moving functionally within a habitual pattern.

\section{Body Memory and Habit}

Walking for me as an uninjured, able-bodied person is a habitual movement and grounded in fundamental habits that rely on body memory, as well as my body's capacity for "feeling itself in movement" (Beith, 2017, p.124). My body knows how to walk, stand, and balance. Therefore, when I walk, I do not have to think about all of these actions anymore. I am not only preconsciously aware of my body, but I am also capable of standing and balancing without any effort. Even though walking seems a natural action, it requires the use of implicit memory, also defined as procedural memory or body memory (Fuchs, 2003; Koch, Fuchs \& Summa, 2012; Hanna, 2015). Such memory is one of the two kinds of long-term memory (declarative memory of facts and procedural memory). It is the memory of the how-to do something and, as with 
declarative memory of supposedly mental acts, does not require any conscious reflection or effort to accomplish physical acts. Thomas Fuchs elaborates six forms of memory, one of which is implicit memory. According to him, this procedural memory

refers to the habitualization of the sensorimotor capacities of the lived body. It allows us to acquire sensorimotor skills and attitudes, to become acquainted with perceptual and movement patterns, and to develop an individual style of interaction with the world. (Koch et al., 2012, p. 275)

Actions such as biking, driving a car, or playing an instrument are defined as procedural because "they are realized in dynamic processes: patterned sequences of movement, wellpracticed habits, skillful handling of instruments, as well as familiarity with patterns of perception" (Fuchs, 2003, p. 12). Procedural memory "does not represent the past, but re-enacts it through the body's present performance. What we once had acquired as skills, habits, and experience have become what we can do today; hence, body memory is our lived past" (Fuchs, 2003, p. 11).

My walk defines who I am in the present even though it is grounded in habits and a history of movement developed in the past. My way of walking is rooted in cultural practices and is a habit developed within my history of movement. Walking is a process and, as such, it is creative. To dance-a-walk, it is neither a spontaneous nor a repetitive movement: it is not a totally improvised movement because I know how to walk, but it is always different because of the non-visible habits that create my walking style.

When I dance-a-walk, I follow a habitual pattern, but I am open to the possible. Dancing-a-walk is therefore always already both concrete and abstract.

David Morris (2004) defines habit as "a style of movement not fully responsive to the world at present, that is shaped by a past history of movement; in some cases we would have to conceive a habit as a movement directed toward a future world that may not even be present" ( $p$. 95). Habits are "not spontaneous acts; rather, they depend on and continue a past. This past is not merely passed over, elapsed; instead, what was a particular, peculiar past remains active in the present as the general form of what it means to live in the present" (Beith, 2017, p. 130).

Walking is part of the learned movements that become basic habits (also grasping, sitting, and standing). These various movements are based on implicit memory as well; some of them are about balancing and shifting the weight. Body memory is therefore a type of memory that "comprises automatic acts that can be performed without thinking and that may occur spontaneously" (Koch et al., 2012, p. 106). It is the wholeness of our bodily abilities and dispositions which develops over the course of our lives (Fuchs 2003; Koch et al., 2012; Koch et al., 2014). All of these actions are not in the foreground of conscious so much as they are the motile conditions of animate consciousness. Walking, standing, or balancing are "fundamental melodies of life $[\ldots]$ inscribed in the body" since they are "forged in the course of infancy and childhood" (Sheets-Johnstone, 2009, p. 255) and are kept alive by memory. In other words, I can simply initiate the walk and trust my body will be there for me and will know what to do. I have faith in my long-term memory, as well as in the physical presence of my own body, even though I am not intentionally attuning to it.

I argue that walking is a good example of "moving in concert" within the body. As Maxine Sheets-Johnstone (2011) points out, "walking is simply a leg movement. Whatever the movement, the whole body is involved in its realization, not only by way of holding or 
stabilizing, but by way of the movement's very unfolding" (p. 392). When I walk on the street, I am able to keep going without bumping into others. My walk is not only about the transfer of weight from one foot to the other; my whole body cooperates to navigate in space. The spatial and bodily awareness allow me to live my daily life in a shared space. More so, to walk, it is necessary that different body parts and different habits work together. My whole body reacts to the instinct, necessity, or command, verbal or not, every time it is needed.

Merleau-Ponty described the process of learning motor habits by using dance as an example. As Don Beith (2017) points out through the example of learning and teaching a spinkick, "perceptual and motor learning are inseparable and they develop together successively in habit formation" (p. 124). In this process of "motor grasping of motor signification," the body draws upon "already acquired movements (such as walking and running)" (Merleau-Ponty, $1945 / 2012$, p. 144). Yet, sometimes, as in the case of dance, the body "brings forth a new core of signification" (p. 147) through gestures that are necessary for life, such as walking. In doing so, it acquires new motor habits by "playing upon these first gestures and passing from their literal to their figurative sense" (p. 147-148).

To better understand the process of learning dancing habits, it is useful to consider the notion of "kinetic melody" (Merleau-Ponty, 1942/1967; Merleau-Ponty, 2003; SheetsJohnstone, 2009). Merleau-Ponty (1963) compared " "kinetic melody" to the activity of the organism since "any change in the end of the melody qualitatively modifies its beginning and the physiognomy of the whole" (p. 107). This concept returns in the courses of the Collège de France (1956-1960) where it is described as the melodic relation between the animal and its Umwelt (Merleau-Ponty, 2003).

Maxine Sheets-Johnstone, following Russian neuropsychologist Aleksandr Romanovich Luria's ideas presented in The Working Brain (1973), uses the term "kinetic melody" as "an experimentally-based concept rooted in the kinetic dynamics of life as normal lived" (SheetsJohnstone, 2009, p. 256). This concept describes an event experienced through the body and with the body as, for instance, in walking a path or writing one's own name. Kinetic melodies are procedural motor memories that describe how to do an action. Since the "information encoded here [in the long-term memory] for a lengthy period of time no longer needs hippocampus intervention" (Hanna, 2015, p. 52), kinesthetic melodies can occur with no effort of recalling the movement. As an example of how kinetic melodies are constituted, Luria (1973) reported observations on the phenomenon of writing:

In the initial stages, for example, writing depends on memorizing the graphic form of every letter. It takes place through a chain of isolated motor impulses, each of which is responsible for the performance of only one element $[\ldots]$ with practice, this structure of the process is radically altered and writing is converted into a single 'kinetic melody,' no longer requiring the memorizing of the visual form of each isolated letter or individual motor impulses for making every stroke. (p. 32)

A similar process occurs when learning a newly crafted or choreographed dance. Each step at first requires effort and memory; the movements appear separated as if the connection between them was missed. With practice, rehearsals, and repetition, the movements are linked together until they become a kinetic melody. Dance is an example of kinetic melodies because "once initiated, the movement flows on by itself" (Sheets-Johnstone, 2009, p. 259). SheetsJohnstone notes also that at any given moment dancers can pay explicit attention to their bodies 
because "our tactile-kinesthetic body is always present, and present along a gamut of possible awarenesses from marginal to maximal. Any time we wish to pay closer attention to it, there it is" (p. 259).

\section{Dancing My Own Walk}

Reading the notes that I took during my research allowed me to reflect on the differences that my body experienced (and experiences) when I walk and when I dance. I describe these findings in the present because they still occur when I experiment with walking and dancing-a-walk. For example, I am aware of my body in space when I walk, as well as the surrounding environment, including others who occupy that space. My pace is faster than when I dance, probably because my focus is on the completion of a goal (i.e., arrive in a specific place, travel a pathway that I might or might not know, go to work, and so on) than on the experience of my body. Walk is, as already discussed, a habit and a functional and task-oriented action that I do not need to practice anymore. It also arises that when I walk I often think about the errands I am going to do. Sometimes I even wonder if people around me are aware of my presence as a researcher and practitioner using her body as a tool, as well as for the purpose of performing. Other times, I simply catch myself dragging my feet on the pavement with a lazy attitude and in a "non-dancer" posture. My legs are just moving. One after the other. One-after-the-other. I feel my hips swinging. Up and down, and down and up. My thoughts move with them. There is no reflection or intention to perceive what is happening. My body. I just let my body be as functional as possible. What is the easiest and faster way to arrive home? Bring me home.

But every time I dance-my-walk, I begin with a short centering practice: a couple of seconds with my eyes closed to change my attitude, a deep breath down into my belly, and a reminder to release my jaw. The use of these techniques, which I have learned over many years of dance and yoga training, allow me to feel my whole body. Surprisingly, as soon as I decide to dance, my spine gets taller and my abdominal muscles contract. Even now, while I am writing, my body is responding to the idea of dancing by getting taller and stronger on the chair. Once I am centered, I begin the dance-walk practice. I can often perceive gravity and the weight of my legs at every step. I experience a voice in my head, as if it were counting and keeping the rhythm of the walk, shifting my focus from my body to the counts. My peripheral vision grows wider and almost enlarged. I notice the world with different eyes. I am able to see more, constantly looking for new movements in the people, the objects, the animals, and in the nature around me. This reminds me of my dance improvisation practice because when I improvise, I am also looking for stimuli from other dancers, in the architecture of the room, and in the music.

In this process, I transform a concrete and context-familiar movement into a stranger action that requires self-aware attention. My walk becomes open to endless possibilities: it is now an abstract, yet concrete, movement.

While dancing-my-walk, I often find myself in the performance mode. I never look down at the pavement as I would normally do when I walk. I never check my phone, texts, or e-mails. At times, I enter a sort of meditative state. One day, I was so immersed in my walk that a bike almost hit me. Immediately, the realization of the escaped accident brought me back to a functional walk. When I dance-my-walk, I shift between being completely and truly open to the surrounding environment to being a performer in an unusual setting. I often smile at the unaware audience. My eyes sustain the gaze of my (unaware) audience for quite a bit of time as if asking, 
“Can you hear me? Can you see me?" In other words, with my dance, I become present and visible to myself, so that the other can see me. One foot in front of the other. Step-Step. I feel the rhythm of my body. I am open to the Others. Do they notice me? Do they know I am dancing for them? I am smiling at them. Sending energy. I am open to these Others. I perceive and feel the people around me. I am keeping eye contact. I am dancing for you, and you, and you. I am challenging you.

As a performer, I want to be seen, and I often feel the urge to break my walk-dance to initiate a new, more visible dance that people might recognize as such. Yet I resist because I am truly committed to my exploration; I repudiate my instinct for the purpose of this research. My goal is to perceive the difference in my body when walking and when dancing-a-walk; therefore, my focus is on the identification of what makes the difference and when the change happens. As a result, the body habits in the foreground always shift. For instance, I focus on different aspects of my movement, on how my body balances, how it stands or steps. How am I balancing? How am I transferring my weight? Rocking from side to side, pouring my weight from side to side. How is it that I cannot balance properly when I am focusing on the transfer of weight?

On the other hand, when I practice how to perceive my walk in the studio or in a safe and contained space, such as an art gallery or my living room, my experience is deeper than when I do it on the street. Indoors, I do not have to protect myself from cars, bikes, or other pedestrians. I can dive deeply into my bodily exploration and sensations. This focus and commitment to the task makes me aware of a variety of movement patterns and small changes that occur in my body (e.g., the shift of weight or the balancing point). I am therefore asking: Is the process of discovering, focusing, and explicitly shifting attention on different aspects of my dancing-walk what makes me dancing? Or it is that as soon as I am self-consciously paying attention to my body, I am not simply walking anymore?

My questions become more relevant if I consider Sheets-Johnstone's argument that we, as humans not suffering from dementia or memory loss, do not find ourselves doing habitual actions (i.e., brushing our teeth or walking), but rather "we are kinaesthetically aware of a certain kinetic dynamics coming to an end" (2009, p. 206). As a non-injured and able-bodied person, I have the option to shift my attention from minimal to maximal. For instance, while I am walking, I can choose to pay attention to the movement of my toes, the swing of my legs, or my habitual walk as a whole.

\section{Conclusion}

I have tried to show how a phenomenological description complicates the relationship between abstract and concrete movements proposed by Maurice Merleau-Ponty in the Phenomenology of Perception. The experience of walking and dancing-a-walk demonstrates how concrete movement are always already abstract and open to the possible. I used the example of Schneider, a World War I brain damage patient described by Merleau-Ponty in Phenomenology of Perception, to establish and then challenge the distinction between abstract and concrete movement. By considering the clinical case, Merleau-Ponty (1945/2012) demonstrated Schneider's preference for concrete movements, which are easier to execute due to their relevance to actual circumstances and need, and his inability to achieve abstract movements (p.106). When asked to perform these abstract movements, Schneider was incapable of moving his body "upon command"; also he could not "describe the position of his body" (p. 105). His 
body was available only "as an amorphous mass in which only real movements introduce divisions and articulations,"(p. 112) whereas for a non-injured subject, the body would immediately be ready and perceived in its context.

I then argued that my walk is transformed into a dance by a self-awareness of the body and its movement. But a methodological and ontological problem arises. Is it possible to investigate my own experience of walking? If I am committing to investigate my walk, am I still in a functional, habitual, and concrete context of familiar behaviour? Or does my body awareness transform my walk into a dance-walk? On a methodological level, I am asking how I can truly be committed and self-aware to the investigation of my walk and dance so that the perceptual shift will not take over the analysis. Every time I experimented with the idea of walking and dancinga-walk, I perceived a shift between a pre-reflective and a reflective level of awareness of my body. While I was dancing-my-walk, I did not consciously reflect on the steps, nor did I think about the movement per se. At the same time, my intention was directed to my walk and to the movement. I argue that the intentional movement is what made me present as a dancer. The dance (my walk) became the focus of my awareness, even though I did not choose to concentrate on it. I experienced my body as an object in a "non-reifying manner" (Legrand \& Ravn, 2009, p. 391). My body reacted physically to the dance by becoming taller, regardless of what I was wearing or carrying with me, stronger, and more engaged.

Every time I dance, my body becomes a home for my dance, and I am often able to perceive the dance that is happening while hosting and inhabiting my body at the same time. I can feel the dance happening inside me. It goes through my body. It is happening to me. Am I dancing or am I danced? What is my capacity to wonder in the wandering? I recall what Peter Bingham, one of my teachers and mentors, told us in one of his morning Contact Improvisation classes: "Dance the question, not the answer." Perhaps, this is my answer. Dancing my walk is teaching me the importance of cultivating and practicing my ability to stay present to the questions and to dance them to the space, the others, and myself, even when it means to keep walking and wandering, one step after the other. By analyzing how I dance my walk, I show that we, as humans, have the ability to make even the most concrete movements abstract. We have the ability to make the familiar strange. In doing so, we may stay inquiringly and creatively in the dance. 


\section{References}

Beith, D. (2017). Moving into being: the motor basis of perception, balance, and reading. In K. Jacobson \& J. Russon (Eds.). Perception and its Development in Merleau-Ponty's Phenomenology. University of Toronto Press.

Fuchs, T. (2003). The memory of the body. Available from https://www.klinikum.uniheidelberg.de/fileadmin/zpm/psychatrie/ppp2004/manuskript/fuchs.pdf

Hanna, J. L. (2015). Dancing To Learn: The Brain's Cognition, Emotion, and Movement. Lanham, MD: Rowman \& Littlefield.

Koch, S. C., Fuchs, T., \& Summa, M. (2014). Body memory and kinesthetic body feedback: The impact of light versus strong movement qualities on affect and cognition. Memory Studies, 7(3), 272-284. doi: 10.1177/1750698014530618.

Koch, S. C., Fuchs, T., Summa, M., \& Müller, C. (2012). Body Memory, Metaphor and Movement. Amsterdam: John Benjamins Publishing Company.

Legrand, D., \& Ravn, S. (2009). Perceiving subjectivity in bodily movement. The case of dancers. Phenom Cogn Sci, 8, 389-408. doi: 10.1007/s11097-009- 9135-5.

Luria, A.R. (1973). The Working Brain. An Introduction to Neuropsychology. (B. Haigh, Trans.). New York: Basic Books Inc.

Merleau-Ponty, M. (1967) The Structure of Behavior. (A. L. Fisher, Trans.). Boston: Beacon Press. (Original work published 1942).

Merleau-Ponty, M. (2003). Nature. Courses notes from the Collège de France. (R. Vallier, Trans.). Evanston: Northwestern University Press.

Merleau-Ponty, M. (2012). Phenomenology of Perception. (D. A. Landes, Trans.). London: Routledge. (Original work published 1945).

Mooney, T. (2011). Plasticity, motor intentionality and concrete movement in Merleau-Ponty. Cont Philos Rev, 44, 359-381. doi: 10.1007/s11007-011-9195-4.

Morris, D. (2004). Sense of Space. Albany, US: SUNY Press.

Romdenh-Romluc, K. (2007). Merleau-Ponty in the power to reckon with the possible. In T. Baldwin (Eds.), Reading Merleau-Ponty on Phenomenology of Perception (pages of chapter). London: Routledge.

Sheets-Johnstone, M. (1999). The Primacy of Movement. Expanded second edition. Amsterdam: John Benjamins. 
Sheets-Johnstone, M. (2009). Kinesthetic memory. In M. Sheets-Johnstone (Eds.), The Corporeal Turn - An Interdisciplinary Reader (pages of chapter). UK: Imprint Academic.

Sheets-Johnstone, M. (2011). From movement to dance. Phenomenology and The Cognitive Sciences, 11, 39-57. doi: 10.1007/s11097-011-9200-8.

Singer, L. (1981). Merleau-Ponty on the concept of style. Man and World, 14, 153-163. doi:10.1007/BF01248467... 